\title{
Diálogos múltiplos em contextos linguísticos e identitários: relato de experiências vivenciadas na comunidade Wakalitesu/Nambikwara da aldeia Três Jacus ${ }^{1}$
}

\author{
Multiple dialogues in language and identities \\ contexts: report of experiences in the wakalitesu/ \\ nambikwara community of the three Jacus village \\ Áurea Cavalcante Santana² \\ Alex Feitosa Oliveira ${ }^{3}$
}

DOI: https://doi.org/10.26512/rbla.v11i1.23954

Recebido em janeiro/2019 e aceito em fevereiro/2019.

Resumo

Relatamos experiências vivenciadas na comunidade Wakalitesu/Nambikwara da aldeia Três Jacus, localizada na Terra Indígena Tirecatinga, no município de Sapezal-MT. O grupo indígena Wakalitesu fala uma língua pertencente à família Nambikwara do Sul e vivencia, na atualidade, múltiplos contextos linguísticos e identitários, em razão da convivência, dentro de sua comunidade, com outros grupos Nambikwara-Halotesu, Mamaindê e Negarotê -, assim como, com outros grupos indígenas falantes de línguas geneticamente distintas - Iranxe, Manoki e Paresi. Nesse contexto étnico plural, a maioria dos moradores da comunidade Três Jacus se autodenomina Wakalitesu. Seu desejo é o de promover e fortalecer a língua indígena, utilizando-a mais amplamente na comunidade e na escola. Com esse intento, fomos convidados por alguns líderes da aldeia Três Jacus para lhes prestar assessoria linguística. Nessa perspectiva, propomos à comunidade aliar as pesquisas linguísticas, desenvolvidas pelos pesquisadores da UFMT, com uma formação continuada para os professores Wakalitesu, organizando encontros, oficinas e seminários.

Palavras-chave: Língua Wakalitesu. Contextos múltiplos. Ortografia.

\begin{abstract}
We report experiences from the Wakalitesu/Nambikwara community of Três Jacus village, located in the Tirecatinga Indigenous Land, municipality of Sapezal-MT. The Wakalitesu indigenous group speaks a language belonging to the South Nambikwara family and is currently living in a multiple linguistic and ethnic context, due to their coexistence with other Nambikwara groups - Halotesu, Mamaindê and Negarote-, and with speakers of languages

\footnotetext{
${ }^{1}$ Trabalho apresentado na modalidade Comunicação Oral no GT Línguas Indígenas durante o XXXIII ENANPOLL, realizado em Cuiabá, MT em junho de 2018.

${ }^{2}$ Professora Adjunto-Nível II do Instituto de Linguagens da Universidade Federal do Mato Grosso - UFMT. E-mail: aurearsh@yahoo.com.br

${ }^{3}$ Mestre em Línguistica pela Universidade Federal do Mato Grosso - UFMT.
} 
belonging to other linguistic families -, Iranxe, Manoki and Paresi. In this plural ethnic context, most of the residents of the Three Jacus community call themselves Wakalitesu. Their desire is to promote and strengthen the indigenous language in the community and at school. With this intent, we were invited by some leaders of the Three Jacus village to give them linguistic support. In this perspective, we have proposed to combine linguistic research, developed by UFMT researchers, with a continuing education for the Wakalitesu teachers, providing the organization of meetings, workshops and seminars.

Keywords: Wakalitesu language. Multiplus contexts. Ortografhy.

\section{Introdução}

Atualmente, os indígenas Nambikwara ${ }^{4}$ vivem em uma área de fronteira interestadual ao Noroeste do estado de Mato Grosso e ao Sul do estado de Rondônia. Habitam, em terras descontínuas, três ecossistemas da região - Serra do Norte, Chapada dos Parecis e Vale do Guaporé, distribuídos em treze Terras Indígenas.

Para Price (1983), mesmo fazendo parte de um povo único, todos os grupos Nambikwara apresentam diferenciações que são bastante significativas. Seguindo o mesmo pensamento, Costa (2000) amplia o nosso entendimento ao declarar que o etnônimo "Nambikwara" alcança, na verdade, uma quantidade de especificidades de diversos grupos que, em alguma medida, não é aceito de maneira uniforme, há dentre esses, alguns que não se autodenominam por este etnônimo.

Sobre as línguas Nambikwara, Telles (2002) apresenta as subdivisões linguísticas da família Nambikwara, declarando que há três ramos linguísticos: Nambikwara do Norte e Nambikwara do Sul que são compostos por várias outras línguas e o ramo Sabanê, formado por uma única língua. Assim, de acordo com a autora, as línguas estão agrupadas da seguinte forma:

-Nambikwara do Sul - Hahãitesú, Alãntesú, Waikisú, Wasúsu, Katitãulhú (Sararé), Saxuentesú, Halotesú, Wakalitesú, Siwxaisú, Nesú, Kithãulhú;

-Nambikwara do Norte - Latundê, Lakondê, Mamaindê e Negarotê;

-Sabanê - Sabanê.

Diante dessa diversidade cultural e linguística dos povos Nambikwara, destacamos a situação da comunidade Wakalitesu, da aldeia Três Jacus - Terra Indígena Tirecatinga, localizada no município de Sapezal, em Mato Grosso. Nesta comunidade iniciamos o Projeto de Pesquisa intitulado: Estudos de Línguas Nambikwara: Múltiplas Convivências na Aldeia Três Jacus - Sapezal, Mato Grosso, vinculado ao Programa de Pós-Graduação em Estudos de

\footnotetext{
${ }^{4}$ Como recorrente na denominação dos povos indígenas, o termo Nambikwara não é pertencente a nenhuma língua falada pelo grupo, é, na realidade, de origem Tupi, e significa curiosamente "buraco na orelha" ("nambi" = orelha; "quara" = buraco) (Santana, 2010).
} 
Linguagem (PPGEL/UFMT) e ao Grupo de Estudos, Descrição e Documentação de Línguas Indígenas (GEDDELI).

Assim, a nossa pretensão é apresentar, neste trabalho, nossas experiências de convivência e pesquisa junto à comunidade Wakalitesu Nambikwara, iniciadas em 2016.

\section{Sobre a aldeia Três Jacus}

Os grupos tradicionais Nambikwara da região do Cerrado mato-grossense são os Halotesu e os Wakalitesu. De acordo com Busatto (2003), o grupo Halotesu se concentrava, em sua maioria, no vale do rio Juína, afluente da margem esquerda do rio Juruena. Já os Wakalitesu estavam localizados, principalmente, na margem oposta do rio Juruena e na bacia dos rios Sapezal e Papagaio (Busatto 2003).

Mais recentemente, com a chegada de outros grupos indígenas à região, houve uma política de ocupação do território e, consequentemente a fixação de grupos em "Terras Indígenas". Com o propósito de garantia de território contínuo, algumas etnias, mesmo pertencentes a grupos étnicos diferentes, ficaram numa mesma Terra Indígena, a exemplo da TI Tirecatinga, onde se fixaram os Wakalitesu/Nambikwara, os Manoki, os Paresi e os Terena" (OPAN 2015:11).

Hoje, os Wakalitesu, em grande maioria, vivem na aldeia Três Jacus e, de acordo com dados da Prefeitura do município de Sapezal, MT, somam cerca de 86 indivíduos. A aldeia possui aproximadamente treze residências físicas, um prédio escolar - Escola Indígena Municipal Wakalitesu, um Posto de Saúde e um Centro Cultural.

De acordo com os dados apresentados em Oliveira (2018), a língua Wakalitesu é, entre as línguas indígenas, a majoritária na comunidade Três Jacus. Há, nesse mesmo espaço, a língua Halotesu, ocupando o segundo lugar em número de falantes, ambas pertencentes ao ramo Nambikwara do Sul. Outro fato que chama a atenção é a existência de falantes das línguas Negarotê e Mamaindê, línguas do ramo Nambikwara Norte. Além dessas línguas da família linguística Nambikwara, identificamos, também, a presença da língua Paresi, pertencente ao tronco Aruak.

Desse modo, consideramos a existência de um plurilinguismo de convivência. Mas ainda que haja a convivência dessas línguas indígenas, os estudos de Oliveira (2018) indicam que o uso português está se propagando, principalmente, entre os mais jovens, intensificando o processo de deslocamento linguístico. Por outro lado, percebe-se o interesse por parte dos professores e de algumas lideranças da comunidade pela manutenção da língua Wakalitesu, por meio da escola, através do ensino da língua indígena. 
Nessa perspectiva, a escola surge como um ambiente propagador das atitudes de valorização da língua. Sobre o contexto escolar, Santana (2012:219) expõe que munidos de atitudes positivas os indígenas reafirmam sua identidade. Ao seu modo de ver, é um espaço próprio para a retomada de suas tradições, propiciando, assim, a retomada de memórias linguísticas e culturais:

O espaço escolar pode, sim, se constituir em um lugar de fortalecimento e valorização da língua indígena, desde que as propostas e metodologias estejam voltadas para uma educação intercultural e transdisciplinar.

\section{Vivências na aldeia Três Jacus}

Nos últimos anos, a comunidade Wakalitesu da aldeia Três Jacus tem se preocupado com a presença da língua indígena na escola. Os professores são da própria comunidade e o ensino ocorre em língua portuguesa. No entanto, há por parte dos professores e lideranças daquela comunidade a preocupação em estabelecer uma ortografia específica para a língua Wakalitesu com o intento de inserir a língua materna indígena na escola.

Nesse contexto, fomos convidados pela comunidade para assessorá-la, ajudanda-a a definir uma ortografia para a língua Wakalitesu. Propomos para a comunidade Três Jacus um Projeto de Pesquisa, já mencionado: Estudos de Línguas Nambikwara: Múltiplas Convivências na Aldeia Três Jacus - Sapezal, Mato Grosso. Neste projeto, propomos integrar as pesquisas do Programa de Pós-Graduação em Estudos da Linguagem - PPGEL / UFMT com a formação em linguística para os professores e demais pessoas da comunidade. Assim, ambos, pesquisa e formação estariam voltadas para a descrição, documentação, registro e ações de fortalecimento e vitalização da língua Wakalitesu.

Nosso primeiro contato com a comunidade de Três Jacus ocorreu em junho de 2016. Naquele momento, tivemos a oportunidade de conversar com os moradores (anciãos, lideranças, professores, pais, alunos e outros residentes), apresentar nossa proposta de trabalho e solicitar a anuência para a realização do projeto de pesquisa. A proposta foi aceita por todos que ali estavam.

Nesse encontro, para nossa surpresa, os indígenas propuseram o uso da grafia "Nambikwara". Fizeram questão de salientar o nome Nambikwara, escrito com $\mathrm{k}$ e w, pois, segundo eles, assim é o certo ${ }^{5}$. Aprovaram que usássemos o seguinte termo: "língua Wakalitesu Nambikwara", pois assim estaríamos privilegiando a

\footnotetext{
${ }^{5} \mathrm{Na}$ tentativa de uniformizar a grafia dos nomes indígenas, em 1954, a Associação Brasileira de Antropologia (ABA) sugeriu o etnônimo Nambikúara. No entanto, na atualidade ainda são utilizadas várias grafias, mas não quisemos, naquele momento em que a comunidade estava tão embebida de identidade, entrar no mérito dessa discussão e acatamos a proposta da grafia sugerida por eles.
} 
identidade Wakalitesu. E assim temos feito.

Desde então, as atividades e ações desenvolvidas em campo não ficam restritas à descrição da língua, a convivência e os registros de campo têm se caracterizado em momentos valiosos de reflexões e aprendizados. E Pimentel da Silva (2009:111) acrescenta: "ensinar e aprender uma língua significa ativar a imensa gama de significados que já estão embutidos nos sistemas culturais". Nessa perspectiva, acrescenta Mori (2012:259), “a responsabilidade do linguista não se limita apenas à língua que estuda, mas também à comunidade falante dessa língua, revendo sua participação nos processos de manutenção e revitalização das línguas ameaçadas de extinção". Assim, os encontros com a comunidade Wakalitesu têm sido sempre permeados de trocas para ambos, pesquisadores e comunidade.

\section{Seminário de Estudos Linguísticos na Comunidade Três Jacus}

As atividades de pesquisa de campo têm se caracterizado pela visita, contato, entrevistas e vivências na comunidade. E a realização de seminários de estudos linguísticos também têm se mostrado úteis, tanto pela necessidade de oferecer acompanhamento técnico/pedagógico para que os professores e alunos indígenas possam romper barreiras do conhecimento sistêmico de suas línguas de convivência, quanto para promover reflexões sobre sua condição linguística e aliar questões pertinentes ao ensino das línguas dentro da comunidade.

Detalhamos, a seguir, momentos sui generis de vivência e aprendizado linguísticos em atividades e metodologias desenvolvidas durante os dois Seminários de Estudos Linguísticos já realizados na comunidade.

\section{Os Seminários de Estudos Linguísticos}

Os Seminários de Estudos Linguísticos consistem em propostas de estudo e pesquisas desenvolvidos pelos pesquisadores e estudantes vinculados ao Grupo de Estudos, Descrição e Documentação de Línguas Indígenas (GEDDELI) e com a orientação e formação linguística de professores e demais pessoas que vivem na aldeia Três Jacus.

\section{Seminário de Estudos Linguísticos: Vivências e Experiências com a Língua Wakalitesu}

O primeiro seminário contou com a presença de um grupo bastante diversificado da comunidade, do qual participaram homens, mulheres, adolescentes e crianças. Além dos que participaram efetivemente do encontro, estiveram conosco alguns líderes da comunidade dispostos a contribuir com as discussões. 
O $1^{\circ}$ Seminário contou com uma parte teórica e reflexiva e outra prática, com os seguintes conteúdos norteadores:

-Princípios Básicos da Linguística.

-Princípios da Gramática Universal.

-Noções de Variação Linguística e Neologismos.

-Reflexões sobre o ensino de línguas.

- Comentários sobre a escrita e ortografia das línguas indígenas.

-Noções de Fonética - O Alfabeto Fonético Internacional (AFI).

-Sons da língua Wakalitesu.

\section{Abertura do I Seminário de Estudos Linguísticos - Aldeia Três Jacus}

Segundo D'Angelis (2013:338), quando se trabalha assessorando os indígenas nas questões linguísticas, é preciso desmistificar algumas concepções já arraigadas, como: "a ilusão da transparência" entre som e a letra na representação da escrita; a ideia de que o linguista não indígena é um "poderoso decifrador da língua"; e, ainda, a premissa de que a "língua dominante" (no caso do Brasil, o português) é superior, é mais estruturada, é a correta. Para D'Angelis, é preciso valorizar a intuição do falante nativo na avaliação das escritas ortográficas e também demonstrar/discutir com os professores alfabetizadores, sobre as interferências previsíveis no uso de uma segunda língua e acrescenta: "para isso o professor terá de alcançar algum conhecimento de fonética e, principalmente de fonologia" (2013:339).

Baseados nessas premissas, iniciamos a conversa sobre esses conteúdos norteadores comentando sobre a diferença entre som, fonema e grafema e as implicações na ortografia, dando exemplos em português, inglês, Chiquitano, Xavante etc. Houve participação de alguns que fizeram perguntas e comparações com a língua Wakalitesu. Aproveitando o entusiasmo do grupo e a presença dos mais velhos, começamos a listar no quadro os sons da língua e os grafemas que estão sendo utilizados por eles e, a partir de observações preliminares, elaboramos uma tabela de sons (não os analisamos como fonemas) e conversamos sobre os possíveis "problemas" na representação daqueles sons. Combinamos que eles deveriam observar e anotar todas as palavras com estes sons "mais difíceis" para que nos próximos encontros pudéssemos trabalhar e observar melhor todas as ocorrências.

Também discutimos noções básicas de Linguística com os temas: língua, linguagem e fala. Ao refletirmos sobre a origem da língua e da linguagem, surgiu o assunto do mito da criação. Os participantes disseram que tinham um mito da criação e resolveram contar. Pedimos permissão para gravar e o $\mathrm{Sr}$. Paulo Nambikwara fez um grande relato, contou o mito da criação e também 
outros mitos relacionados. O relato foi muito interessante e foi acompanhado com atenção por todos.

Aproveitamos o momento para orientar os professores sobre a importância de adotarem metodologias contextualizadas em busca do conhecimento, da troca de experiências com os anciãos e do contato com as histórias, mitos, cantos etc.

\section{Sr. Paulo Nambikwara conta Mitos}

No contexto de reflexões sobre a língua Wakalitesu, algumas características específicas da língua Wakalitesu ${ }^{6}$ como as diferenças tonais, os classificadores, por exemplo, os quais chamam a atenção tanto por serem especificidades da língua (não observadas no português), quanto pela dificuldade que os professores encontram no registro ortográfico. Por isso a preocupação em rever a ortografia para que os alunos aprendam a língua materna ancestral, estimulando e elevando a autoestima dos novos aprendizes com a percepção de que sua língua tem valor, tem elementos gramaticais importantes como qualquer outra língua detentora de prestígio. Neste primeiro seminário o encantamento dos participantes se deu pela "descoberta" da criação das novas palavras na língua.

\section{Conversando sobre "as novas palavras"}

Ao refletimos sobre homogeneidade das línguas e também sobre os processos de criação de renovação das línguas, todos gostaram do tema "neologismos", da criação de novas palavras na língua. Aproveitamos o entusiasmo para buscar e relacionar no quadro exemplos de "palavras novas" na língua Wakalitesu. O professor Natanael Sawentesu escreveu algumas palavras no quadro, como: bacia, televisão, relógio, caneta, vestido... e explicou cada uma delas, mostrando que umas tinham "marcas" da língua e outras não.

\section{Exemplos de Novas Palavras/ Neologismos na Língua Wakalitesu}

Os professores e outros participantes ficaram muito entusiasmados com a possibilidade de criarem palavras na língua materna para coisas como celular, quadro etc e se animaram no exercício linguístico. Isto contribui para a reflexão sobre a estrutura da língua Wakalitesu.

\section{Seminário de Estudos Lingúisticos: Ortografia e Jogos Didáticos com a Língua Wakalitesu}

No $2^{\circ}$ Seminário, realizado em março de 2018, também contamos com

${ }^{6}$ Denominamos "características específicas" aquelas características da língua Wakalitesu que não são observadas na língua portuguesa. 
a presença dos idosos, dos professores e das crianças. Iniciamos as nossas discussões e reflexões sobre a ortografia da língua Wakalitesu, retomando o alfabeto fonético da língua, "esboçado" no I Seminário de Estudos Linguísticos, ocorrido em dezembro de 2016. A partir do esboço do "alfabeto" e das palavras ilustrativas da representação dos fonemas fomos revisando a escrita/ representação dos sons. Neste momento, a presença do Sr. Lídio Nambikwara, um ancião, foi muito proveitosa, pois o professor recorria sempre a ele para encontrar as palavras que melhor pudessem ilustrar os exemplos dos sons na língua Wakalitesu.

As discussões foram muito interessantes e as maiores dúvidas ficaram por conta da representação dos " $r$ " e " $t$ ", aparentemente ${ }^{7}$ palatalizados, da aproximante "y" e das vogais nasais e laringalizadas. Durante essas conversas, mencionamos que seria muito interessante um encontro com outros grupos Nambikwara aparentados para conversarem sobre ortografia e outras questões linguísticas que os interessassem, buscando uma escrita "mais unificada possível", compartilhando uma ortografia.

Não tivemos muito sucesso em nossas proposições. Percebemos que os indígenas gostariam de ter um alfabeto próprio daquela comunidade e tinham pressa com respeito a isso. Assim, buscando algumas propostas em materiais didáticos existentes, como a Apostila das palavras em língua portuguesa e da língua Nambikwara (2004) e a Cartilha Nossa língua Nambikwara (2007) ${ }^{9}$, elaboramos um esboço de um alfabeto. Propusemos tratá-lo como experimental para que se treinasse a escrita e fossem anotadas as dúvidas para uma discussão nos próximos encontros.

Alguns exercícios de escrita foram experimentados e, com isso, já se fez correção no alfabeto. Explicamos que o processo é assim mesmo, que não se consegue ter uma escrita tal qual a fala, e que mais tarde, com um estudo e observações mais detalhadas da língua, haverá necessidade de se criar algumas regras de escrita. Sugeriu-se que todos tentassem utilizar essa ortografia, com o objetivo de experimentá-la.

\section{Discussão sobre o Alfabeto}

\footnotetext{
${ }^{7}$ Utilizamos o termo "aparentemente" por ainda não ter com clareza a descrição fonética e fonológica da língua.

${ }^{8}$ Apostila das palavras em língua portuguesa e da língua Nambikwara - O material em questão foi criado em 2004 pelas professoras indígenas Leontina e Terezinha. Em seguida, a Secretaria de Educação teve o cuidado de realizar uma revisão e impressão para o seu uso em sala de aula.

${ }^{9}$ Nossa língua Nambikwara (cartilha) - A cartilha elaborada por Jaime Nambikwara é o material encontrado mais recente, datado de 2007. Os professores da aldeia apontaram que há algumas dificuldades para a utilização desta cartilha, principalmente, por suas representações gráficas.
} 
Na sequência das atividades, apresentamos algumas propostas lúdicas para trabalhar o vocabulário da língua Wakalitesu/Nambikwara. A proposta foi a de confeccionar os jogos com a colaboração dos próprios participantes. Desse modo, todos foram levados a buscar figuras de alguns campos lexicais, como os animais, frutas e partes do corpo, por exemplo. Com as figuras destacadas, pudemos elaborar três modelos de materiais.

\section{Dominó (figuras e nomes)}

No dominó, os participantes devem juntar as figuras de animais com os nomes escritos na língua Wakalitesu. Este tipo de dominó também pode funcionar como jogo de memória, envolvendo atividades de associação dos aspectos oral e escrito da língua.

\section{O jogo de dados com sufixos}

$\mathrm{O}$ jogo de dados consiste em um cubo/dado com um sufixo escrito em cada um dos lados e o jogador deve formar palavras com os sufixos indicado no lado que ficar para cima. Este tipo de atividade lúdica incentiva os aprendizes a pesquisar e memorizar os nomes na língua que está aprendendo. E o interessante é que este jogo pode ter múltiplas funções, pode ser jogado individualmente, em grupo, com versões orais e também escritas, conforme orientação e planejamento do professor e/ou do orientador.

\section{A Palavra é... (jogo de sílabas)}

Neste jogo, um tabuleiro é apresentado com figuras e sílabas soltas para forma o nome das figuras apresentadas. Tanto no tabuleiro, quanto no jogo de dado, os participantes interagem com a escrita e obtêm informações sistêmicas da língua, ampliando assim os conhecimentos sobre o seu funcionamento.

\section{Demonstração dos Jogos Didáticos}

Partindo da premissa de que toda aprendizagem é uma realização interativa (Pimentel da Silva: 2009), os professores foram aprendendo que diferentes práticas e metodologias podem ser adotadas no aprendizado e ensino da língua. Aprenderam, também, que tais práticas devem estar voltadas para o diálogo cultural e intercultural. Neste sentido, os jogos, os quebra-cabeças e outras atividades interativas, criadas pelos professores, podem consistir em excelentes instrumentos didáticos de ensino, aprendizagem e encantamento da língua.

Por todos os comentários registrados nos questionários e nas observações livres, concluímos que os Seminários vêm cumprindo os objetivos propostos. Os participantes se mostram entusiasmados com a possibilidade da construção de novos materiais pedagógicos, como registrado no diário de campo de 
Oliveira (2018): “A indígena chegou com uma sobrinha e seu filho. Jennifer e eu mostramos os materiais para eles e foi muito curioso acompanhar o movimento dos jogos com eles. A mãe olhou para as crianças e disse: Esses jogos aqui são pra vocês aprenderem mais a língua" (Diário de Campo 2018: 13).

\section{Considerações Finais}

A possibilidade de aliar a pesquisa a atividades voltadas para a comunidade e para a formação de professores tem sido muito positiva, pois temos podido conhecer melhor os problemas relativos à escrita da língua, assim como compartilhar e trocar experiências com a comunidade.

Percebemos, no pouco tempo que tivemos de reflexão, que os professores indígenas carecem de formação linguística para lidar com suas respectivas línguas na escola.

As atividades com jogos e encenações, por exemplo, incentivaram o exercício da língua em sua modalidade oral e em sua modalidade escrita, estimulando professores e alunos a pesquisarem e a conhecerem mais a sua língua nativa. Em um projeto de retomada ou de revitalização e de valorização da língua é importante que haja motivação para o uso dessa língua por parte da comunidade e o estímulo das pessoas para o uso do pouco do que sabem da língua ou do que estão aprendendo sobre ela. (Pimentel da Silva 2009:135). É importante, em um processo de valorização e fortalecimento da língua, que as atividades propostas sejam prazezoras. $\mathrm{Na}$ experiência em pauta, não só os alunos, mas todos da comunidade foram descobrindo o valor e a beleza da língua, tal como observa Pimentel da Silva (2009:132): "o prazer pela língua, pelas suas riquezas é relevante na aprendizagem de línguas ameaçadas".

\section{Referências}

Busatto, Ivar L. V. 2003. Os Nambikwara da Terra Indigena Tirecatinga-Mato Grosso: Agricultura, Espécies e Variedades Tradicionais. Dissertação de Mestrado. Faculdade de Agronomia e Medicina Veterinária, Universidade Federal de Mato Grosso.+

Costa, Anna Maria R. F. M. 2002. Senhores da Memória: uma história do Nambiquara do cerrado. Cuiabá: UNICEN Publicações.

D’Angelis, Wilmar da Rocha. 2013. Fonética e Fonologia na Formação de Professores Indígenas. Fórum Linguístico. V. 10, n.4: 324-341.

Mori, Angel Corbera.2012. A Relação entre Sujeito Linguista e os Sujeitos Falantes das Línguas Indígenas. Discurso, Sujeito e Memória pp. 259-269 - Campinas: Pontes Editores.

Oliveira, Alex Feitosa de. 2018. Diário de Campo. Cuiabá, MT.

Oliveira, Alex Feitosa de. 2018. Línguas Conviventes: aspectos sociolinguísticos 
na aldeia Três Jacus - comunidade Wakalitesu/Nambikwara. Dissertação de Mestrado - Instituto de Linguagens, Universidade Federal de Mato Grosso. OPAN. Operação Amazônia Nativa. (Org.). 2015. Plano de Gestão da Terra Indígena Tirecatinga - Sapezal, Mato Grosso: OPAN.

Pimentel da Silva, Maria do Socorro. 2009. Reflexões Sociolinguísticas sobre Linguas Indígenas Ameaçadas. Goiânia: Ed. UCG.

Price, David. 1983. Pareci, Cabixi, Nambiquara: a Case Study in the Western Classification of Native Peoples. Paris: Journal de la Société des Américanistes, v. 69:129-148.

Santana, Áurea Cavalcante. 2014. Linguas Cruzadas, Histórias que se Mesclam: ações de documentação, valorização e fortalecimento da língua Chiquitano no Brasil. Jundiaí: Paco Editorial.

Santana, Nelivaldo C. 2010. Descrição preliminar da nasalidade em Tawandê e outras línguas Nambikwára do Norte. Dissertação de Mestrado em Letras - Universidade Federal de Pernambuco.

Telles, Stela. 2002. Fonologia e Gramática Latundê/Lakondê. Tese de Doutorado - Amsterdam: Vrije Universiteit Amsterdam. 